\title{
PROTAGONIST
}

\section{Mycobacterium avium subspecies paratuberculosis is a cause of Crohn's disease}

\author{
J Hermon-Taylor
}

Mycobacterium avium subspecies paratuberculosis (MAP) belongs to the $M$ avium complex (MAC). MAC occur widely in the environment and inhabit normal animal and human intestine. MAC do not usually cause disease unless the host is debilitated. $M A P$ is a pathogen and causes chronic inflammation of the intestine in many animals, including primates. $M A P$ is closely related genetically to other MAC but possesses additional DNA such as IS900, the $h s p \mathrm{X}$ region, and the low \%GC genetic element "GS", which are associated with its pathogenic phenotype. Further genetic elements related to pathogenicity may be revealed by the whole genome sequencing of $M A P$ currently underway at the University of Minnesota. A recent review and extensive bibliography is available. ${ }^{1}$

$M A P$ can colonise animals for years without causing disease. Chronic inflammation of the intestine (Johne's disease) may emerge after a long latent period, particularly when animals are stressed. Regional lymph nodes, liver, and lung are also involved. Histopathological features vary between animals and between different organs in the same animal. ${ }^{2} M A P$ disease in animals ranges from pluribacillary to paucimicrobial, like leprosy in humans. ${ }^{3}$ Terminal ileum and adjacent colon are commonly affected but segmental lesions in the small gut as well as colonic and rectal involvement also occur. Animals usually die of their infection and although perforation, stricture, and fistulation are not usually found in Johne's disease, these features occur in regional ileitis and colitis in dogs and pigs. ${ }^{4}$ In experimental infection, $M A P$ demonstrates a distinct tissue tropism and will cause chronic inflammation of the intestine if given intravenously or subcutaneously. $^{67}$

With the opportunity to amplify in intensely farmed domestic livestock for over a century, $M A P$ may have undergone an adaptive diversification. Genotyping of $M A P$ has so far revealed 28 different strains, including those favouring a particular host such as sheep or cattle. ${ }^{8}$ The herd prevalence of $M A P$ infection in Western Europe and North America is in the range 21-70\%. ${ }^{910}$ Reinfection of new generations of young animals comes by passage of $M A P$ from parent to offspring in milk, and from contaminated farm environments. Wildlife reservoirs contribute to environmental contamination. ${ }^{11}$ Subclinically infected cows secrete $M A P$ in their milk. $M A P$ is more robust than $M$ tuberculosis and can survive commercial pasteurisation conditions, commonly $72^{\circ} \mathrm{C}$ for 15 seconds. ${ }^{1} M A P$ is present in retail pasteurised milk in Britain. ${ }^{12} M A P$ survives in the environment and is probably conveyed to humans in water supplies. ${ }^{1}$ Colonisation of the human intestine is cumulative. As with other mycobacteria, $M A P$ may remain in a state of dormancy for years. Inflammatory disease develops in those who have an inherited or acquired susceptibility. Clinical disease may be triggered by intercurrent infection and by physical or psychological trauma.

In conventional media, $M A P$ ranges from very slow growing to unculturable. $M A P$ is more resistant to chemical and enzymatic lysis than other organisms. ${ }^{1}$ It is present in the intestine of a proportion of normal subjects and can be detected in a majority of full thickness surgical samples of Crohn's disease gut if the correct culture and IS900 polymerase chain reaction (PCR) methods are used. ${ }^{13}{ }^{14} M A P$ in Crohn's disease is present in low abundance and in a tough $\mathrm{ZN}$ negative form putatively coated with methylated and acetylated fucose. ${ }^{1} M A P$ in humans can minimise immune recognition, and tests of antibody or cell mediated immunity using crude lysates of laboratory cultured $M A P$ or other MAC, with some exceptions, have not distinguished general immune reactivity to MAC in Crohn's disease from that in normal subjects. ${ }^{1}$ Highly significant immune recognition in Crohn's disease can be detected if molecules bearing $M A P$ specific epitopes or those shared with other mycobacteria are used. ${ }^{15}$

$M A P$ in Crohn's disease does not have a conventional mycobacterial cell wall. Pathogenic mechanisms and drug susceptibilities are not like tuberculosis. Intracellular $M A P$ probably causes an immune dysregulation with transmural inflammation resulting from a perturbed immune response to leakage of enteric organisms and food residues into the gut wall. Without killing $M A P$, improvements following immune suppression or modulation, elemental diets, and antibiotics active against enteric bacteria are seldom lasting. $M A P$ infection in animals is not eradicated by anti-tuberculosis drugs. ${ }^{1}$ The failure of a lengthy controlled trial of rifampicin, isoniazid, and ethambutol to confer benefit ${ }^{16}$ is consistent with what has long been known of the resistance of MAC to such agents in vitro and in vivo, and the non-bacillary phenotype of MAP in Crohn's disease. Crohn's disease is not healed by rifampicin and streptomycin which have broad activity against enteric organisms. Four outcome analyses have all shown that a substantial proportion of people with Crohn's disease improve with tissue healing when treated with a combination of
Department of Surgery, St George's Hospital Medical School, London SW17 ORE, UK J Hermon-Taylor

Correspondence to: Dr J Hermon-Taylor. jhermon@sghms.ac.uk

Accepted for publication 21 July 2000 
Debate

\section{Summary}

- Mycobacterium avium subspecies paratuberculosis (MAP) is a member of the $M$ avium complex (MAC). Unlike other MAC, MAP is a specific cause of chronic inflammation of the intestine of a broad range of histopathological types, affecting many species of animals including subhuman primates.

- MAP can colonise animals for years without causing clinical disease. Such subclinically infected animals shed MAP in their milk and onto pastures. The herd prevalence of subclinical MAP infection in Europe and North America is reported to be in the range $21-70 \%$.

- $M A P$ is present in retail pasteurised milk in Britain and is probably also conveyed in water supplies.

- MAP is harboured in the ileocolonic mucosa of a proportion of normal subjects and can be demonstrated in full thickness samples of gut wall in the majority of patients with Crohn's disease if the correct culture and PCR methods are used.

- As with other MAC, MAP infections are difficult to eradicate and the organisms are resistant to most standard anti-tuberculosis drugs. Rifabutin and clarithromycin are more active against MAP and about two thirds of patients with active Crohn's disease will go into remission with healing of the intestine when treated with a combination of these agents.

rifabutin and clarithromycin. ${ }^{17-20}$ These drugs also have a broad antibacterial action but are more active against MAC and $M A P$. A controlled trial of rifabutin, clarithromycin, and clofazimine began in Australia in September 1999. Therapeutic $M A P$ vaccines for immune mediated microbial clearance are needed.

1 Hermon-Taylor J, Bull TJ, Sheridan JM, et al. Causation of Crohn's disease by Mycobacterium avium subspecies paratuberculosis. Can J Gastroenterol 2000;14:521-39.

2 Buergelt CD, Hall C, McEntee K, et al. Pathological evaluation of paratuberculosis in naturally infected cattle. Vet Pathol 1978;15:196-207.

3 Clarke CJ. The pathology and pathogenesis of paratuberculosis in ruminants and other species. J Comp Pathol 1997;16:217-61.

4 Emsbo P. Terminal or regional ileitis in swine. Nord Vet Med 1951;3:1-28.

5 Van Kruiningen HJ. Canine colitis comparable to regiona enteritis and mucosal colitis of man. Gastroenterology 1972;62:1128-42.
6 Twort FW, Ingram GLY. A Monograph on Johne's Disease. London: Bailliere, Tindall and Cox, 1913.

7 Larsen AB, Miller JM, Kermal RS. Subcutaneous exposure of calves to Mycobacterium paratuberculosis compared with intravenous and oral exposures. Am J Vet Res 1977;38:1669-71.

8 Pavlik I, Horvathova A, Dvorska L, et al. Standardisation of restriction fragment length polymorphism analysis for Mycobacterium avium subspecies paratuberculosis. $J$ Microbiol Methods 1999;38:155-67.

9 Wells SJ, Ott SL, Garber LP, et al. Johne's disease on US dairy operations: results from the NAHMS dairy 96 study. In: Chiodini RJ, Hines ME, Collins MT, eds. Proceedings of the Fifth International Colloquium on Paratuberculosis 1996. Rehoboth, MA, USA: International Association for Paratuberculosis, 1996:140-2.

10 Nielsen SS, Thamsborg SM, Houe H, et al. Bulk-tank milk ELISA antibodies for estimating the prevalence of paratuberculosis in Danish dairy herds. Prev Vet Med 2000;44: $1-7$.

11 Beard PM, Henderson D, Daniels MJ, et al. Evidence of paratuberculosis in fox (Vulpes vulpes) and stoat (Mustela erminea). Vet Rec 1999;145:612-13.

12 Report of the Scientific Committee on Animal Health and Animal Welfare, European Commission. Possible links between Crohn's disease and paratuberculosis. http:// europa.eu.int/comm/dg24/health/sc/scah/ outcome_en.html

13 Sanderson JD, Moss MT, Tizard MLV, et al. Mycobacterium paratuberculosis DNA in Crohn's disease tissue. Gut 1992;33:890-6.

14 Schwartz D, Shafran I, Romero C, et al. Use of short-term culture for identification of Mycobacterium avium subsp paratuberculosis in tissue from Crohn's disease patients. Clin Microbiol Infect 2000;6:303-7.

15 Cohavy O, Harth G, Horwitz M, et al. Identification of a novel mycobacterial histone $\mathrm{H} 1$ homologue (HupB) as an antigenic target of panca monoclonal antibody and serum immunoglobulin a from patients with Crohn's disease. Infect Immun 1999;67:6510-17.

16 Thomas GAO, Swift GL, Green JT, et al. Controlled trial of antituberculous chemotherapy in Crohn's disease: a five year follow up study. Gut 1998;42:497-500.

17 Gui GPH, Thomas PRS, Tizard MLV, et al. Two-yearoutcomes analysis of Crohn's disease treated with rifabutin and macrolide antibiotics. I Antimicrob Chemother 1997;39:393-400.

18 Borody TJ, Pearce L, Bampton PA, et al. Treatment of severe Crohn's disease (CD) using rifabutin-macrolideclofazimine combination: interim report. Gastroenterology 1998;114:A938.

19 Shafran I, Piromalli CS, Naser S, et al. Rifabutin and macrolide antibiotic treatment in Crohn's patients identified serologically positive for Mycobacterium avium subspecies paratuberculosis. Gastroenterology 2000;118:A782.

20 Douglass A, Cann PA, Bramble MG. An open pilot study of antimicrobial therapy in patients with unresponsive Crohn's disease. Gut 2000;46(suppl II):A11. 


\title{
Mycobacterium avium subspecies paratuberculosis is a cause of Crohn's disease
}

\author{
P Quirke
}

The hypothesis that Mycobacterium paratuberculosis is the cause of Crohn's disease has been with us for over 80 years. ${ }^{1}$ Yet the hypothesis remains controversial and unproved. ${ }^{2-5}$ In spite of advances in molecular techniques such as polymerase chain reaction (PCR) which has shed light on the infectious basis of many other diseases (Whipple's disease, Helicobacter pylori, hepatitis C, etc.), the cause of Crohn's disease remains unknown.

The competing hypotheses are widely known:

(1) Genetic predisposition.

(2) Other infectious agents such as measles virus or an unknown agent.

(3) Abnormal autoimmune reaction to antigen (s).

(4) Environmental factors within the gut related either to dietary factors or the microbiological environment.

There is little controversy over a genetic component to the disease but this hypothesis alone cannot explain the increasing incidence. It appears most likely that the cause of Crohn's disease is a combination of a genetic predisposition to the disease and one or more of the alternative hypotheses. For the infectious disease hypothesis to be proved for any organism, Koch's postulates need to be fulfilled. It is clear that to date these have yet to be met for $M$ paratuberculosis. Van Kruiningen $^{2}$ has extensively reviewed the data on culture of $M$ paratuberculosis in Crohn's disease, experimental transmission of Crohn's disease, and inoculation with $M$ paratuberculosis, and has found the evidence wanting. There is also no evidence of direct transmission from animal to humans, despite the frequent occurrence of $M$ paratuberculosis (up to $54 \%$ in some cattle herds ${ }^{3}$ ) and Johne's disease in cattle, its detection in cows milk, and the presence of $M$ paratuberculosis in a number of other animals. High risk groups susceptible to transmission of the disease would be families of cattle and sheep farmers, abattoir workers, veterinary surgeons, and possibly gastroenterologists. To date, there is no such evidence.

There are pathological similarities between Johne's disease and Crohn's disease but there are also many features that are not found. These are eloquently detailed by Van Kruiningen ${ }^{2}$ and will not be repeated here. He suggests that the closest human disease to Johne's disease is the Mycobacterium avium intracellular infections of AIDS patients, not Crohn's disease.

For an agent to cause a disease such as Crohn's disease it should be reliably detectable within the tissues of diseased patients. $M$ paratuberculosis has been grown from individual cases of Crohn's disease in several centres ${ }^{67}$ but it has also been grown from individuals without the disease and individuals with ulcerative colitis. There are now over 24 papers addressing the detection of $M$ paratuberculosis using $\mathrm{PCR}^{8-31}$ and these are summarised in table 1 . Most of these papers use the IS900 target sequence stated to be "uniquely specific" for $M$ paratuberculosis. ${ }^{3}$ Other targets claimed to be specific are GS and hspX. ${ }^{3}$ The frequency of detection of IS 900 ranges from $0 \%$ to $87.5 \%$ in non-inflammatory bowel disease tissues, $0 \%$ to $100 \%$ in ulcerative colitis, and $0 \%$ to $100 \%$ in Crohn's disease. Thus DNA from the " $M$ paratuberculosis specific" IS900 sequence has been detected in patients with Crohn's disease but also frequently in patients with ulcerative colitis and normal individuals. However, other conflicting studies have shown no detectable DNA from individuals with Crohn's disease when searching for IS900. To summarise these studies, 14 of the 24 papers from table 1 found no $M$ paratuberculosis in Crohn's disease against 10 which did. The negative studies contained 323 Crohn's patients and the positive studies 188. Thus the balance both in terms of the number of studies and number of patients evaluated favours the absence of $M$ paratuberculosis in Crohn's disease tissues. There are a number of possible explanations for these contradictory findings.

\section{For false positive findings}

IS900 sequences are not specific for $M$ paratuberculosis but can be found in other environmental or animal borne mycobacteria. ${ }^{32}$ These results in animals were obtained using primers described by Professor Hermon-Taylor's group. This group identified the false positive bacteria as derived from mycobacteria with close sequence homology on their 16S rRNA of $M$ paraffinicum (97.8\%) or $M$ scrofulaceum (97.1-99.45\%). This increases the likelihood that the range of PCR results is due to detection of cross reacting sequences from other common mycobacterial sequences.

Cross contamination from $M$ paratuberculosis cultures or previous PCR amplified sequences generated in the same laboratory can occur. In our own experience we found that our early positive results ${ }^{33}$ could not be confirmed when we enhanced our PCR anticontamination methods.

\section{For false negative findings}

- Poor PCR design, reactions, or detection methods.

- Insensitive PCR reactions.
Academic Unit of Pathology, University of Leeds, Leeds LS2 9JT, UK

P Quirke

Correspondence to: Professor P Quirke. philq@pathology.leeds.ac.uk

Accepted for publication 5 September 2001 
Debate
Table 1 Summary of the frequency of polymerase chain reaction studies for the presence or absence of Mycobacterium paratuberculosis in Crohn's disease (CD), ulcerative colitis (UC), and non-inflammatory bowel disease (IBD) tissues. These are shown in order of date of publication

\begin{tabular}{|c|c|c|c|c|}
\hline Reference & Target & Non-IBD & $U C$ & $C D$ \\
\hline Rosenburg et al $1991^{8}$ & Not stated, not IS900 & $0 / 6(0 \%)$ & nd & $0 / 21(0 \%)$ \\
\hline Wu et al $1991^{9}$ & $\begin{array}{l}\text { Pan mycobacterial } \\
\text { sequences }\end{array}$ & nd & nd & $0 / 20(0 \%)$ \\
\hline Sanderson et al $1992^{10}$ & IS 900 & $5 / 40(12.5 \%)$ & $1 / 23(4.3 \%)$ & $26 / 40(65 \%)$ \\
\hline Dell'Isola et al $1994^{11}$ & IS900 & $7 / 24(29 \%)$ & $1 / 5(20 \%)$ & $13 / 18(72 \%)$ \\
\hline Lisby et al $1994^{12}$ & IS 900 & $3 / 28(11 \%)$ & $2 / 10(20 \%)$ & $11 / 24(46 \%)$ \\
\hline Fidler et al $1994^{13}$ & $\begin{array}{l}\text { IS } 900 \text {. Also detected non } \\
M \text { paratuberculosis } \\
\text { sequences }\end{array}$ & $0 / 20(0 \%)$ & $0 / 10(0 \%)$ & $4 / 31(13 \%)$ \\
\hline \multirow[t]{2}{*}{ Suenaga et al $1995^{14}$} & IS 900 & $14 / 16(87.5 \%)$ & $11 / 18(61 \%)$ & $10 / 10(100 \%)$ \\
\hline & GroEL & $14 / 16(87.5 \%)$ & $11 / 18(61 \%)$ & $10 / 10(100 \%)$ \\
\hline Rowbotham et al $1995^{15}$ & IS900 & $1 / 26(4 \%)$ & $0 / 49(0 \%)$ & $0 / 68(0 \%)$ \\
\hline Murray et al $1995^{16}$ & IS 900 & $0 / 15(0 \%)$ & $2 / 15(13 \%)$ & $2 / 9(22 \%)$ \\
\hline \multirow[t]{2}{*}{ Kreuzpaintner et al $1995^{17}$} & $16 \mathrm{~S}$ rRNA & $0 / 1(0 \%)$ & nd & $0 / 4(0 \%)$ \\
\hline & Culture & $0 / 23(0 \%)$ & nd & $0 / 23(0 \%)$ \\
\hline Erasmus et al $1995^{18}$ & IS900 & $4 / 35(11 \%)$ & nd & $10 / 26(38 \%)$ \\
\hline Mishina et al $1996^{19}$ & IS900 mRNA & $0 / 2(0 \%)$ & $4 / 4(100 \%)$ & $8 / 8(100 \%)$ \\
\hline Frank and Cook $1996^{20}$ & IS 900 & $0 / 11(0 \%)$ & nd & $0 / 23(0 \%)$ \\
\hline \multirow[t]{2}{*}{ Dumonceau et al $1996^{21}$} & Mycobacteria & $13 / 23(57 \%)$ & $6 / 13(46 \%)$ & $17 / 36(47 \%)$ \\
\hline & $M$ paratuberculosis & $0 / 23(0 \%)$ & $0 / 13(0 \%)$ & $0 / 36(0 \%)$ \\
\hline Dumonceau et al $1997^{22}$ & $\begin{array}{l}M \text { paratuberculosis } 16 \mathrm{~S} \\
\text { rRNA }\end{array}$ & $0 / 22(0 \%)$ & $0 / 10(0 \%)$ & $0 / 31(0 \%)$ \\
\hline \multirow{2}{*}{ Al-Shamali et al $1997^{23}$} & IS 900 & $0 / 21(0 \%)$ & $0 / 6(0 \%)$ & $0 / 10(0 \%)$ \\
\hline & MP2 & $0 / 21(0 \%)$ & $0 / 6(0 \%)$ & $0 / 10(0 \%)$ \\
\hline Riggio et al $1997^{24}$ & IS900 & $0 / 12(0 \%)$ & nd & $0 / 7(0 \%)$ \\
\hline Clarkston et al $1998^{25}$ & IS 900 & $0 / 11(0 \%)$ & $0 / 5(0 \%)$ & $1 / 21(5 \%)$ \\
\hline \multirow[t]{2}{*}{ Cellier et al $1998^{26}$} & $\begin{array}{l}16 \mathrm{~S} \text { rRNA any } \\
\text { mycobacteria }\end{array}$ & $2 / 20(10 \%)$ & $1 / 27(4 \%)$ & $2 / 47(4 \%)$ \\
\hline & IS900 & $0 / 20(0 \%)$ & $0 / 27(0 \%)$ & $0 / 47(0 \%)$ \\
\hline Chiba et al $1998^{27}$ & IS900 & $0 / 3(0 \%)$ & $0 / 14(0 \%)$ & $0 / 30(0 \%)$ \\
\hline Kanazawa et al $1999^{28}$ & IS900 & $0 / 13(0 \%)$ & $0 / 4(0 \%)$ & $0 / 13(0 \%)$ \\
\hline Tiveljung et al $1999^{29}$ & $16 \mathrm{~S}$ rRNA & $0 / 11(0 \%)$ & nd & $3 / 11(27 \%)$ \\
\hline${ }^{\star}$ Ikonomopoulos et al $2000^{30}$ & $\begin{array}{l}\text { IS } 1110 \text { element and } \\
\text { probed } 16 \mathrm{~S} \text { rRNA }\end{array}$ & nd & $1 / 1(100 \%)$ & $7 / 20(35 \%)$ \\
\hline †Gibson et al $2000^{31}$ & IS900 & $0 / 12(0 \%)$ & nd & $0 / 3(0 \%)$ \\
\hline
\end{tabular}

${ }^{\star} M$ paratuberculosis sequences in sarcoidosis were also found. $+0 / 21$ from orofacial granulomatosis.

nd, not done.

- Very low numbers of infecting organisms below the limit of detection of the assay.

- Inability to extract DNA from mycobacteria because strong walls inhibit release of DNA.

- Granulomatous versus non-granulomatous disease as $M$ paratuberculosis is claimed to be more frequently found in granulomatous disease.

- Selection of wrong age groups, wrong types of material, or delay in processing material.

- Regional variations in $M$ paratuberculosis.

Many of the reasons given for negative findings can be easily overcome by good study design. The use of good positive controls and demonstration of positive signals with such organisms will exclude poor PCR reaction design. Many authors have successfully amplified material from control cultured mycobacteria and strains such as LINDA isolated from a Crohn's patient so this problem does not appear to be important. Several of the assays in the negative published papers claim very high sensitivity on serial dilutions of control bacteria making it unlikely that target concentration is a problem. Other papers have reproduced the extraction methods of Professor Herman-Taylor ${ }^{10}$ with successful detection but to no avail. ${ }^{15}$ Others have specifically looked at granulomatous and non-granulomatous disease. Papers have appeared from all over the world with contradictory results from the same countries, making regional differences unlikely. The only way to establish the truth of the presence or absence of $M$ paratuberculosis DNA is a properly funded, carefully planned, blinded, international multicentre study with good controls and free exchange of PCR methods that test multiple targets in the $M$ paratuberculosis genome using agreed "optimised" methods. Cultures of "pathogenic" mycobacteria from patients with Crohn's and closely related strains of mycobacteria need to be available to evaluate the sensitivity and specificity of tests for the chosen targets. Because of the data of Cousins and colleagues ${ }^{32}$ the positive IS900 data must be confirmed by restriction digestion or sequencing and by detection of other sequences characteristic of $M$ paratuberculosis. The material evaluated must come from different hospitals and comprise fresh rapidly sampled diseased tissues from a range of granulomatous and non-granulomatous cases of Crohn's disease from the small and large intestine and from resections and biopsies. Each sample should have two parallel samples taken from well characterised cases of ulcerative colitis and age matched controls of biopsied or surgically removed non-inflammatory bowel disease material. It would be preferable for adjacent material to be available for histological assessment and for in situ hybridisation studies. Such a study needs to take place under the supervision of an independent data monitoring committee.

If DNA detection is controversial the recent claims for the detection of $M$ paratuberculosis by in situ hybridisation in Johne's disease ${ }^{3435}$ and subsequently in human diseased tissues ${ }^{36}$ are intriguing. If confirmed by other laboratories, this may represent very important evidence for the causality of Crohn's disease by $M$ paratuberculosis. Interestingly, the results of in situ hybridisation 
using an IS900 sequence found positive signals in a similar number to some of the PCR studies, namely $7 / 37(18.9 \%)$ of Crohn's samples, $2 / 21$ $(9.5 \%)$ ulcerative colitis samples, and $0 / 22(0 \%)$ normal samples. Signal was seen in macrophages and myofibroblasts. This study did not test the specificity of the in situ hybridisation against the cross reacting organisms described by Cousins and colleagues ${ }^{32}$ and only derived significance by selecting idiopathic inflammatory bowel disease cases versus non-idiopathic inflammatory bowel disease, and granulomatous Crohn's disease cases versus non-granulomatous Crohn's. Further studies of this nature are urgently required to confirm or refute these results but issues of specificity must be properly addressed. Newer techniques of in situ $\mathrm{PCR}^{37}$ and Taqman in situ $\mathrm{PCR}^{38}$ may contribute to the debate. Sanna and colleagues $^{37}$ have developed an in situ PCR for $M$ paratuberculosis using IS900 and successfully applied it to Johne's disease. Positive results in Crohn's disease would be encouraging especially if the distribution matched that of Hulten and colleagues. ${ }^{36}$ However, multiple targets would need to be used to confirm specificity. Studies of a range of antibodies to mycobacteria and $M$ paratuberculosis using immunocytochemistry have as yet failed to detect $M$ paratuberculosis. ${ }^{39-41}$

If $M$ paratuberculosis is the cause of Crohn's disease why is it that antimycobacterial agents do not eradicate the disease? To date the literature is inconclusive. A recent meta-analysis ${ }^{42}$ found 29 papers but only eight were proper randomised placebo controlled trials and the number of patients totalled only 352 in all studies. Only one study had more than 51 patients. They stated that there was insufficient evidence to be sure of the effects of antibiotic therapy for Crohn's disease but that the combined data suggest that antibiotic therapy may help maintain remission. However, these data were based on two trials with only 89 patients in total and the hypothesis was not derived a priori. Thus we do not really know the value of antimycobacterial therapy, and the proponents of this hypothesis are open to criticism that after 80 years we have yet to see a positive, properly conducted therapeutic trial. Even if antimycobacterials improve outcome, is it due to direct action on $M$ paratuberculosis or an effect on the general bacterial flora, and most importantly, do antimycobacterials cure the disease? This vitally important question is unanswered. Once the diagnostic testing trial has been completed, a major properly powered trial of effective antimycobacterial antibiotics versus broad spectrum antibiotics versus placebo in patients identified as having $M$ paratuberculosis should be initiated with patients being followed by PCR to confirm the continued presence or eradication of the organism.

The beginning of large scale dissection of the pattern of RNA expression by cDNA arrays ${ }^{43}$ of diseased Crohn's tissues, its comparison with those of other human mycobacterial infections and, when the bovine genome becomes available, of the mucosal response in Johne's disease, will provide more circumstantial evidence for or against the role of $M$ paratuberculosis in Crohn's disease. Early evidence ${ }^{44}$ is intriguing in that it points to activation of the antibacterial defensin genes 5 and 6 in Crohn's disease tissues but these are also raised in ulcerative colitis.

With a possible 90000 people with Crohn's disease in the UK and an estimated cost of treatment of Crohn's disease to the NHS at over $£ 200$ million per year, the question of whether $M$ paratuberculosis is involved in Crohn's disease needs to be resolved once and for all by large carefully designed studies of detection and treatment. More resources need to be directed at this disease to answer this important question. After 80 years the evidence for $M$ paratuberculosis as the cause of Crohn's is still circumstantial and definitive studies remain to be performed.

1 Dalziel TK. Chronic intestinal enteritis. BMJ 1913;ii:106870.

2 Van Kruiningen HJ. Lack of support for a common etiology in Johne's disease of animals and Crohn's disease in humans. Inflamm Bowel Dis 1999;5:183-91.

3 Hermon-Taylor J, Bull TJ, Sheridan JM, et al. Causation of Crohn's disease by Mycobacterium avium subspecies paratuberculosis. Can J Gastroenterol 2000;14:521-39.

4 Chamberlin W, Graham DY, Hulten K, et al. Mycobacterium avium subsp. paratuberculosis as one cause of Crohn's disease. Aliment Pharmacol Ther 2001;15:33746.

5 Van Kruiningen HJ. Lack of support for a common etiology in Johne's disease of animals and Crohn's disease in humans. Inflamm Bowel Dis 1999;5:183-91.

6 Moss MT, Sanderson JD, Tizard ML, et al. Polymerase chain reaction detection of Mycobacterium paratuberculosis and Mycobacterium avium subsp silvaticum in long term cultures from Crohn's disease and control tissues. Gut 1992;33:1209-13.

7 Chiodini RJ, Van Kruiningen HJ, Thayer WR et al. Possible role of Mycobacteria in inflammatory bowel diseases. An unclassified Mycobacterium species isolated from patients with Crohn's disease. Dig Dis Sci 1984;29:10739.

8 Rosenburg WM, Bell JI, Jewell DP. Mycobacterium paratuberculosis DNA cannot be detected in Crohn's disease tissues. Gastroenterology 1991;100:611A.

9 Wu SW, Pao CC, Chan J, et al. Lack of mycobacterial DNA in Crohn's disease tissues. Lancet 1991;337:174-5.

10 Sanderson JD, Moss MT, Tizard ML, et al. Mycobacterium paratuberculosis DNA in Crohn's disease tissue. Gut 1992;33:890-6.

11 Dell'Isola B, Poyart C, Goulet O, et al. Detection of Mycobacterium paratuberculosis by polymerase chain reaction in children with Crohn's disease. J Infect Dis 1994;169: 449-51.

12 Lisby G, Andersen J, Engbaek K, et al. Mycobacterium paratuberculosis in intestinal tissue from patients with Crohn's disease demonstrated by a nested primer polymerase chain reaction. Scand J Gastroenterol 1994; 29:923-9.

13 Fidler HM, Thurrell W, Johnson NM, et al. Specific detection of Mycobacterium paratuberculosis DNA associated with granulomatous tissue in Crohn's disease. Gut 1994; 35:506-10.

14 Suenaga K, Yokoyama Y, Okazaki K, et al. Mycobacteria in the intestine of Japanese patients with inflammatory bowel disease. Am J Gastroenterol 1995;90:76-80.

15 Rowbotham DS, Mapstone NP, Trejdosiewicz LK, et al. Mycobacterium paratuberculosis DNA not detected in Crohn's disease tissue by fluorescent polymerase chain reaction. Gut 1995;37:660-7.

16 Murray A, Oliaro J, Schlup MM, et al. Mycobacterium paratuberculosis and inflammatory bowel disease: frequency distribution in serial colonoscopic biopsies using the polymerase chain reaction. Microbios 1995;83:21728. 
Debate

17 Kreuzpaintner G, Kirschner P, Wallner A, et al. Mycobacteria of Runyon groups I, II and IV do not play an aetiological role in Crohn's disease. Eur $J$ Gastroenterol Hepatol 1995;7:1177-82.

18 Erasmus DL, Victor TC, van Eeden PJ, et al. Mycobacterium paratuberculosis and Crohn's disease. Gut 1995;36: 942.

19 Mishina D, Katsel P, Brown ST, et al. On the etiology of Crohn disease. Proc Natl Acad Sci USA 1996;93:981620.

20 Frank TS, Cook SM. Analysis of paraffin sections of Crohn's disease for Mycobacterium paratuberculosis using polymerase chain reaction. Mod Pathol 1996;9:325.

21 Dumonceau JM, Van Gossum A, Adler M, et al. No Mycobacterium paratuberculosis found in Crohn's disease using polymerase chain reaction. Dig Dis Sci 1996;41: 421-6.

22 Dumonceau JM, Van Gossum A, Adler M, et al. Detection of fastidious mycobacteria in human intestines by the polymerase chain reaction. $J$ Clin Microbiol Infect Dis 1997;16:358-63

23 Al-Shamali M, Khan I, Al-Nakib B, et al. A multiplex polymerase chain reaction assay for the detection of Mycobacterium paratuberculosis DNA in Crohn's disease tissue. Scand J Gastroenterol 1997;32:819-23.

24 Riggio MP, Gibson J, Lennon A, et al. Search for Mycobacterium paratuberculosis DNA in orofacial granulomatosis and oral Crohn's disease tissue by polymerase chain reaction. Gut 1997;41:646-50.

25 Clarkston WK, Presti ME, Petersen PF, et al. Role of Mycobacterium paratuberculosis in Crohn's disease: a prospective, controlled study using polymerase chain reaction. Dis Colon Rectum 1998;41:195-9.

26 Cellier C, De Beenhouwer H, Berger A, et al. Mycobacterium paratuberculosis and Mycobacterium avium subsp. silvaticum DNA cannot be detected by PCR in Crohn's disease tissue. Gastroenterol Clin Biol 1998;22:675-8.

27 Chiba M, Fukushima T, Horie Y, et al. No Mycobacterium paratuberculosis detected in intestinal tissue, including Peyer's patches and lymph follicles, of Crohn's disease. J Gastroenterol 1998;33:482-7.

28 Kanazawa K, Haga Y, Funakoshi O, et al. Absence of Mycobacterium paratuberculosis DNA in intestinal tissues from Crohn's disease by nested polymerase chain reaction. J Gastroenterol 1999:34:200-6.

29 Tiveljung A, Soderholm JD, Olaison G, et al. Presence of eubacteria in biopsies from Crohn's disease inflammatory lesions as determined by $16 \mathrm{~S}$ rRNA gene-based PCR. $J$ Med Microbiol 1999;48:263-8.

30 Ikonomopoulos JA, Gorgoulis VG, Kastrinakis NG, et al. Sensitive differential detection of genetically related mycobacterial pathogens in archival material. Am J Clin Pathol 2000;14:940-50.

31 Gibson J, Riggio M, McCreary C, et al. Looking for Mycobacterium paratuberculosis DNA by polymerase chain reaction (PCR) in orofacial granulomatosis (OFG) and oral Crohn's disease tissue in an Irish population. Ir Med J 2000;93:218.

32 Cousins DV, Whittington R, Marsh I, et al. Mycobacteria distinct from Mycobacterium avium subsp. paratuberculosis isolated from the faeces of ruminants possess IS900like sequences detectable IS900 polymerase chain reaction: implications for diagnosis. Mol Cell Probes 1999;13:431-42.

33 Quirke P, Dockey D, Taylor GR, et al. Detection of Mycobacterium paratuberculosis in Crohn's disease. Gut 1991;32:A572.

34 Hulten K, Karttunen TJ, El-Zimaity HM, et al. Identification of cell wall deficient forms of M. avium subsp. Paratuberculosis in paraffin embedded tissues from animals with Johne's disease by in situ hybridization. J Microbiol Methods 2000;42:185-95.

35 Hulten K, Karttunen TJ, El-Zimaity HM, et al. In situ hybridization method for studies of cell wall deficient $M$. paratuberculosis in tissue samples. Vet Microbiol 2000;77:513-8.

36 Hulten K, El-Zimaity HM, Karttunen TJ, et al. Detection of Mycobacterium avium subspecies paratuberculosis in Crohn's diseased tissues by in situ hybridization. Am J Gastroenterol 2001;96:1529-35.

37 Sanna E, Woodall CJ, Watt NJ, et al. In situ-PCR for the detection of Mycobacterium paratuberculosis DNA in paraffin-embedded tissues. Eur J Histochem 2000;44: 179-84.

38 Lewis FA, Ross W, Quirke P. In situ PCR incorporating simultaneous sequence detection results in a higher specificity for the localisation of specific gene sequences. $J$ Pathol 2000;190:33-33A.

39 Kobayashi K, Blaser MJ, Brown WR. Immunohistochemical examination for mycobacteria in intestinal tissues from patients with Crohn's disease. Gastroenterology 1989;96:1009-15.

40 Tanaka K, Wilks M, Coates PJ, et al. Mycobacterium paratuberculosis and Crohn's disease. Gut 1991;32:435.

41 Cartun RW, Van Kruiningen HJ, Pedersen CA, et al. An immunocytochemical search for infectious agents in Crohn's disease. Mod Pathol 1993;6:212-19.

42 Borgaonkar MR, Maclntosh DG, Fardy JM. A metaanalysis of antimycobacterial therapy does not increase the rate of maintenance of remission in Crohn's disease. Am J Gastroenterol 2000;95:725-9.

43 Maughan NJ, Lewis F, Smith V. An introduction to arrays. $J$ Pathol 2001;195:3-6.

44 Lawrance IC, Fiocchi C, Chakravarti S. Ulcerative colitis and Crohn's disease: distinctive gene expression profiles and novel susceptibility candidate genes. Hum Mol Genet 2001;10:445-56. 